\title{
BMJ Open Characteristics of resident physicians accessing a specialised mental health service: a retrospective study
}

\author{
María Dolores Braquehais (D) , ,2 Sebastián Vargas-Cáceres, ${ }^{3}$ Gemma Nieva (D) ,,4 \\ Maria Fernanda Mantilla, ${ }^{5}$ Germán Ortega, ${ }^{4}$ Sergi Valero, ${ }^{1,6}$ \\ Jose Antonio Ramos-Quiroga, ${ }^{2,4}$ Eugeni Bruguera ${ }^{1,4}$
}

To cite: Braquehais MD, Vargas-Cáceres S, Nieva G, et al. Characteristics of resident physicians accessing a specialised mental health service: a retrospective study. BMJ Open 2021;11:e055184. doi:10.1136/ bmjopen-2021-055184

- Prepublication history for this paper is available online. To view these files, please visit the journal online (http://dx.doi. org/10.1136/bmjopen-2021055184).

Received 05 July 2021 Accepted 01 November 2021

Check for updates

(c) Author(s) (or their employer(s)) 2021. Re-use permitted under CC BY-NC. No commercial re-use. See rights and permissions. Published by BMJ.

For numbered affiliations see end of article.

\section{Correspondence to} Dr María Dolores Braquehais; mdbraquehais.paimm@comb. cat

\section{ABSTRACT}

Objectives Little is known about resident physicians being treated at physician health programmes around the world despite the fact that it is a highly demanding training period. This study aims to describe the profiles of resident physicians accessing a specialised mental health service in Spain over a 20-year period and to compare them to consultant-grade physicians.

Design Retrospective observational study.

Setting Medical records of the Galatea Care Programme for Sick Physicians.

Participants 1846 physicians registered at the Barcelona Medical Council-Association and admitted to the programme from January 1998 to December 2018.

Primary and secondary outcome measures Number of admissions, sociodemographic and clinical variables, including medical specialty, main diagnosis and need of hospitalisation.

Results Residents accounted for $18.1 \%(n=335)$ of the sample and admissions increased over the years. Most residents $(n=311 ; 94.5 \%)$ and consultant-grade physicians $(n=1391 ; 92.8 \%)$ were self-referred. The most common specialty among residents was family medicine $(n=107$; $31.9 \%)$, followed by internal medicine $(n=18 ; 5.4 \%)$, paediatrics $(n=14 ; 4.2 \%)$, psychiatry $(n=13 ; 3.9 \%)$ and anaesthesiology $(n=13 ; 3.9 \%)$. Residents, regardless of year of training, mainly asked for help because of adjustment ( $n=131 ; 39.1 \%)$, affective $(n=77 ; 23 \%)$, anxiety disorders $(n=40 ; 18.8 \%)$ and addictions $(n=19$; $5.7 \%$ ). There were no significant differences between groups in the main diagnosis and in the variables related to need of hospitalisation. The percentage of residents accessing the programme was higher than in the reference population registered at the Barcelona Medical Council-Association ( $18.1 \%$ vs $7.6 \%$; $z=7.2, p<0.001)$ as was the percentage of family medicine residents $(31.9 \%$ vs $19.6 \% ; z=5.7, p<0.001$ ).

Conclusions Residents are more likely than consultantgrade physicians to seek help when suffering from mental disorders. Local primary prevention actions since the beginning of their training period and having access to a well-known highly reliable programme may partly explain these findings.

\section{INTRODUCTION}

Becoming a consultant grade specialist is a critical period in a physician's career.

\section{Strengths and limitations of this study}

- This study addresses a very important issue, as residency training is a highly stressful and demanding life period for most physicians, and it analyses two decades of data describing patterns in resident physicians' admissions to a specialised mental health programme.

- Clinical and sociodemographic variables of resident and consultant-grade physicians were compared.

- A supplementary analysis was conducted to ascertain the differences between junior and senior resident physicians.

- Data were also compared with the reference population (physicians, including residents, registered at the Barcelona Medical Council-Association).

- Limitations of this study are its retrospective design, the fact that diagnoses were not obtained after a structured interview, and the lack of data in terms of personality traits and/or other psychosocial aspects.

Many countries offer training programmes that vary according to their health systems' demands and organisations. ${ }^{1-3}$ In Spain, the nationwide medical residency training (MIR, in Spanish 'Médico Interno Residente', MIR) programme was inspired by the 'learn by working' US model. It ranges from 4 to 5 years depending on the specialty. ${ }^{4}$ It is conceived as system of learning through supervised and programmed professional practice for the specialist-in-training to acquire the knowledge, skills, techniques and responsibilities needed to become an independent specialist. ${ }^{5}$ Each resident is assigned a tutor responsible for his/her supervision during the training period. They meet regularly to mentor and supervise the learning process. There is also a systematic performance evaluation throughout this period to ensure the progressive acquisition of the competencies required to become a specialist.

Despite differences between countries, this highly demanding period has been associated 
with a worsening in residents' well-being and healthy habits as well as with a higher risk of developing mental disorders. ${ }^{6}$ During this transitional life stage, young physicians are exposed to several stressors including: heavy workload, sleep deprivation, difficult patients, poor learning environments, relocation issues and living away from family and friends, isolation and social problems, limited free time to relax, financial concerns, cultural and minority issues, information overload and career planning issues. ${ }^{89}$

Although most residents are able to endure these stressful conditions without a negative impact on their mental health, there is increasing evidence of the presence of distress among them during this training period. Some personality traits (neuroticism, perfectionism or obsessive-compulsive traits) and other vulnerability factors, for example, prior personal or familial psychopathology, may increase the risk of suffering from mental disorders under these challenging circumstances. ${ }^{8} 9$ Women residents have been reported to be at a higher risk of developing affective or mental disorders than men ${ }^{10}{ }^{11}$ although these differences are not supported by other studies. ${ }^{612}$ On the other hand, male residents seem to be more likely than women to have suicidal thoughts ${ }^{12}$ and to develop addictive disorders. ${ }^{13-15}$ Among medical residents, prevalence of depressive symptoms is estimated to range from $20.9 \%$ to $43.2 \%,{ }^{16}$ while $7 \%$ to $22 \%$ report having suicidal ideation. ${ }^{17} 18$ With respect to substance misuse, around $20 \%$ of residents may meet criteria for hazardous drinking ${ }^{19}$ and $13 \%$ self-medicate with legal drugs to cope with stress. ${ }^{12}$ In Spain, $18 \%$ of residents are hazardous drinkers, ${ }^{14}$ and between $8 \%$ and $16 \%$ selfmedicate with psychoactive drugs. ${ }^{13}$

Residents may lack support ${ }^{20}$ but a main reason may be that they have internal barriers to help-seeking due to concerns about confidentiality, stigma around mental illness $^{21} 22$ and fear of not being competent, leading, in many cases, to ${ }^{23}$ 'presenteeism' (attendance at work despite ill health), ${ }^{21}$ and to long working hours.$^{21} 22$ The impact of physicians' mental health goes beyond their personal well-being and extends to the quality of care provided to patients, ${ }^{23-25}$ leading to increased difficulties in professional relationships, reduced learning ability, worse patient satisfaction and more medical errors. ${ }^{926-28}$ Characteristics of burnout (poor communication and reduced empathy) run counter to the core principles of patient-centred care. ${ }^{29}$ In fact, physicians who maintain healthy lifestyles are more likely to focus on preventive strategies with their patients. ${ }^{30} 31$

In its 10-year report, the UK Practitioner Health Programme ${ }^{32}$ informed that over the first 14 months of this service, they assisted 297 junior doctors and a much smaller number of self-referred dentists. Overall, 61 doctors were unwell enough to be on sick leave and 5 were suspended or unemployed. Their main complaints were for anxiety, low mood and stress related problems, the majority of which were related to their workplace. The average age of admission to the UK Programme has steadily dropped during their first 10 -year period and the number of women has increased as well.

Currently, prevention services for medical trainees have been developed in some countries. In the USA, the Accreditation Council for Graduate Medical Education (ACGME) requires that postmedical training programmes make assistance services available for all residents. Practical interventions include an enhanced focus on resident well-being through a range of ACGME activities. ${ }^{33}$ Similar programmes have been created and used by residents and faculty members such as those developed by the Oregon Health and Science University ${ }^{34}$ and by the University of California San Diego Healer Education Assessment and Referral (HEAR) programme. ${ }^{35}$ In UK, the Trainee Doctors and Dentist Service, hosted by National Health Service (NHS) Practitioner Health Programme, is a psycho education and support service which aims to offer a range of interventions to support trainees (eg, individual face-to-face support, online cognitive-behavioural therapy, mindfulness and the other groups). ${ }^{32}$ Most jurisdictions in Canada have consolidated a number of services under the banner of a provincial physician health programme (PHP) and they have released a descriptive framework in 2016 to define a series of core services and more standardised programmes for resident and physicians. ${ }^{36}$ In Australia, The Royal Australasian College of Physicians Support Programme provides a professional and confidential counselling service to all fellows and trainees run by Converge International, an Australian institution with qualified professionals in mental health. ${ }^{37}$

The Galatea Care Programme for Sick Physicians (Galatea-PAIMM in Catalan, PAIME in Spanish), launched by the Barcelona Medical Council-Association (COMB) and later extended to the rest of Spain, was the first of its nature developed in Europe back in 1998. The Galatea Foundation has developed several prevention activities to promote self-care among residents, such as workshops, e-learning and clinical sessions, which are an opportunity to share and discuss the causes of stress among resident physicians as well as to learn skills and attitudes to manage them. More than 350 resident physicians have attended these courses to date. The interventions focus not only on the individual but also on the interdisciplinary team where they work. ${ }^{38}$ The Galatea Foundation also offers a mental health service for all health professionals working in Catalonia, including physicians, through the Galatea Care Programme for Sick Physicians developed at the Galatea Clinic. ${ }^{39}$

However, little is known about resident physicians being treated in specialised Physicians' Health Programmes around the world. This study aims to describe the profile of residents admitted to the Galatea Care Programme during a 20-year period and to compare them to consultant-grade physicians. A supplementary analysis is conducted to ascertain the differences between junior and senior residents. Data are also compared with the reference population (physicians, including residents, registered at the Barcelona Medical Council-Association). 


\section{METHODS}

\section{Participants}

The Galatea Care Programme is offered to all physicians registered at Catalan Medical Council-Associations ('Colegios de Médicos' in Spanish, 'Col-legis de Metges' in Catalan). Registration at those institutions is a required condition to practice as a physician.

This is a retrospective study of 1846 medical records of physicians registered at the COMB who asked for help at the Galatea Care Programme for Sick Physicians between January 1998 and December 2018. Residents accounted for $18.1 \%(n=335)$ of the sample. Information about medical specialties of all residents working in Barcelona was provided by the Registration Unit of the COMB. The average of residents per year at the COMB in the 1998-2018 period was 2549. Therefore, resident physicians were approximately $7.6 \%$ of all registered doctors $(\mathrm{N}=33453)$. Globally, physicians admitted to the programme $(\mathrm{n}=1846)$ represented $5.5 \%$ of all physicians accredited by the COMB while residents $(n=335)$ were $18.1 \%$.

With regards to resident physician specialty, the average number of residents registered at the COMB to become Family Medicine specialist for the study period was 500 (19.6\% of all registered residents). Around $10.3 \%$ of all physicians registered at the COMB reported being a family practitioner although this information is not essential for registration. The Catalan Department of Health estimates that $21 \%$ of physicians working at the Public Health System are family physicians.

Type of referral to the Galatea Care Programme can be divided into voluntary versus non-voluntary. Voluntary referrals only include clear self-referrals to the programme while non-voluntary referrals come after: (1) induced referral (by a colleague or relative); (2) confidential information received by the COMB; or, (3) formal complaint to the COMB due to malpractice issues being identified.

\section{Clinical and sociodemographic variables}

Clinical and sociodemographic variables were obtained from each medical record. Sociodemographic variables were recorded at admission, including medical specialty. Mental health disorders were diagnosed by a psychiatrist during the first 3 initial interviews according to the Diagnostic and Statistical Manual of Mental Disorders (DSMIV-TR) criteria. ${ }^{40}$

\section{Statistical analyses}

Besides descriptive statistics, Chi-Square $\left(\chi^{2}\right)$ test was used to compare dichotomous variables between groups. Student's t-test was used to compare quantitative variables. Due to low cells sample size, diagnoses were grouped into four main categories (affective, substance use, anxiety and 'other' mental disorders). ORs with $95 \%$ Confidence Intervals (CIs) were used to analyse the relationship between binary variables.
Residents were initially compared with other physicians accessing the programme. As some consultant-grade physicians did not have a MIR specialist title $(n=295)$, an additional analysis was conducted excluding them in order to test if differences between both groups remained without significant changes. Another analysis was conducted comparing younger and senior residents' profiles.

In addition, we performed one-sample z-test in order to test differences between resident proportion sample and resident population; $p$ values were calculated for twotailed comparison.

A multivariate logistic regression analysis was executed to identify the final significant variables, emerged as significant in the previous bivariate, when differentiating between residents and consultant-grade physicians. All hypothesis tests were two-tailed and conducted with an alpha of 0.05. Statistical analyses were conducted using STATA V.15.

\section{Patient and public involvement}

There was no patient or public involvement in the design, conduct, reporting or dissemination plans of this research.

\section{RESULTS}

Of all the physicians, including residents, admitted to the programme during that period $(\mathrm{N}=1846)$, the majority were women $(\mathrm{n}=1038 ; 56.2 \%)$, half of them were married or living with a partner $(\mathrm{n}=949 ; 51.4 \%)$, most had children $(n=969 ; 53.5 \%)$, their mean age was $43.6(\mathrm{SD}=10.9)$ years, the vast majority were self-referred $(n=1702$; $93.1 \%)$, had a regular salary $(\mathrm{n}=1595 ; 88.2 \%)$ and a third were on a sick leave $(n=586 ; 33.5 \%)$. Overall, the most prevalent diagnosis at admission was adjustment disorder $(\mathrm{n}=639 ; 34.6 \%)$, followed by mood disorders $(\mathrm{n}=481$; $26.1 \%)$, substance use disorders $(\mathrm{n}=262 ; 14.2 \%)$, anxiety disorders $(n=237 ; 12.8 \%)$, personality disorders $(n=49$; 2.7\%) and schizophrenia and other psychotic disorders $(n=45 ; 2.4 \%)$. Regarding hospitalisation during the first treatment episode, almost a fifth of the whole sample were admitted to the inpatient unit $(\mathrm{n}=348 ; 18.9 \%)$. Each hospitalisation lasted a mean of 32.5 Standard Deviation, $(\mathrm{SD}=22.7)$ days and more than a third of the sample $(n=128 ; 36.8 \%$ of those ever hospitalised and $6.9 \%$ of the total) needed to be rehospitalised. Differences between consultant-grade physicians and residents are summarised in table 1.

The prevalence of mental disorders was different between groups, as substance use disorders were less frequent among residents than in consultant-grade physicians while anxiety disorders and adjustment disorders were more prevalent among junior doctors. No differences between resident and consultant grade physicians were found with regards to variables related to the need of hospitalisation during the first treatment episode. 
Table 1 Sociodemographic, occupational, main diagnosis and hospitalisation comparison between resident and consultantgrade physicians

$\begin{array}{lll}\begin{array}{l}\text { Resident } \\ \text { physicians } \\ \left(n_{1}=335\right) \%(n)\end{array} & \begin{array}{l}\text { Consultant-grade } \\ \text { physicians } \\ \left(n_{2}=1511\right) \%(n)\end{array} & \text { Statistics } \\ & & \end{array}$

\begin{tabular}{|c|c|c|c|c|c|}
\hline & $\left(n_{1}=335\right) \%(n)$ & $\left(n_{2}=1511\right) \%(n)$ & $\chi^{2}$ & $p$ value & OR (95\% Cl) \\
\hline \multicolumn{6}{|c|}{ Sociodemographic and occupational variables } \\
\hline Women & $64.2(215)$ & $54.5(823)$ & 10.12 & 0.001 & $0.67(0.52$ to 0.85$)$ \\
\hline Self-referrals & $94.5(311)$ & $92.8(1391)$ & & 0.315 & 1.34 (0.8 to 2.24$)$ \\
\hline In a relationship (yes) & $25.7(86)$ & $57.1(863)$ & 107.27 & $<0.001$ & $0.26(0.2$ to 0.34$)$ \\
\hline Children (yes) & $11(36)$ & $62.9(933)$ & 289.16 & $<0.001$ & $13.8(9.6$ to 19.8$)$ \\
\hline Sick leave (yes) & $20.9(67)$ & $36.4(519)$ & 27.63 & $<0.001$ & 2.17 (1.62 to 2.9$)$ \\
\hline \multirow[t]{2}{*}{ Regular salary (yes) } & $96.6(315)$ & $86.3(1280)$ & 26.28 & $<0.001$ & $0.22(0.12$ to 0.41$)$ \\
\hline & & & $t$ & $p$ & Cohen's $d^{*}$ \\
\hline Age, mean (SD) & $31.1(5.6)$ & $46.4(9.7)$ & 38.74 & $<0.001$ & 1.93 \\
\hline \multicolumn{6}{|l|}{ Main diagnosis at admission } \\
\hline & & & $\chi^{2}$ & $p$ value & \\
\hline Substance use disorders & $5.7(19)$ & $16.1(243)$ & 40.6 & $<0.001$ & \\
\hline Mood disorders & $23(77)$ & $26.7(404)$ & & & \\
\hline Adjustment disorders & $39.1(131)$ & $33.6(508)$ & & & \\
\hline Anxiety disorders & $18.8(63)$ & $11.5(174)$ & & & \\
\hline Personality disorders & $3.9(13)$ & $2.4(36)$ & & & \\
\hline $\begin{array}{l}\text { Schizophrenia and other } \\
\text { psychotic disorders }\end{array}$ & $2.1(7)$ & $2.5(38)$ & & & \\
\hline \multicolumn{6}{|l|}{ Hospitalisation } \\
\hline Hospitalised & $16.4(55)$ & $19.4(293)$ & 1.4 & 0.237 & 0.82 (0.6 to 1.12$)$ \\
\hline \multirow[t]{2}{*}{ Need for rehospitalisation } & $6.2(21)$ & $7.1(107)$ & 0.007 & 0.934 & 1.07 (0.6 to 1.94$)$ \\
\hline & & & $t$ & $p$ value & Cohen's $d^{*}$ \\
\hline $\begin{array}{l}\text { Number of days (first } \\
\text { hospitalisation), mean (SD) }\end{array}$ & $35.2(18.24)$ & $32(23.42)$ & 0.96 & 0.34 & 0.15 \\
\hline
\end{tabular}

${ }^{*}$ Cohen's d are calculated for quantitative variables.

Residents admitted to the Galatea Care Programme were overrepresented when compared with residents registered at the COMB $(\mathrm{z}=7.2, \mathrm{p}<0.001)$. With regards to specialty, the largest proportion of admitted residents were in training to become family medicine specialists $(\mathrm{n}=107 ; 31.9 \%)$, followed by those from internal medicine $(\mathrm{n}=18 ; 5.4 \%)$, paediatrics $(\mathrm{n}=14 ; 4.2 \%)$, psychiatry $(\mathrm{n}=13$; $3.9 \%)$ and anaesthesiology $(n=13 ; 3.9 \%)$. The percentage of family medicine residents in was also higher than thoseregistered at the COMB $(31.9 \%$ vs $19.6 \%$; $\mathrm{z}=5.7$, $\mathrm{p}<0.001)$. Concerning consultant-grade family physicians admitted to the Galatea Care Programme, these doctors were also disproportionately represented when compared with the reference population registered at the COMB ( $20.3 \%$ vs $10.3 \%$; $\mathrm{z}=12.8, \mathrm{p}<0.001$ ); see figure 1 .

Both residents and consultant-grade physician admissions to the programme increased over the years. Significantly, during the first 5years (1998-2002) resident admissions were infrequent (see figure 2).

When performing a logistic regression analysis for the whole sample, only younger age, a different status from married or living with a partner, remained statistically significant (see table 2). These findings were similar when grouping all main diagnoses into two main categories (addictions vs non-addictive mental disorders). There

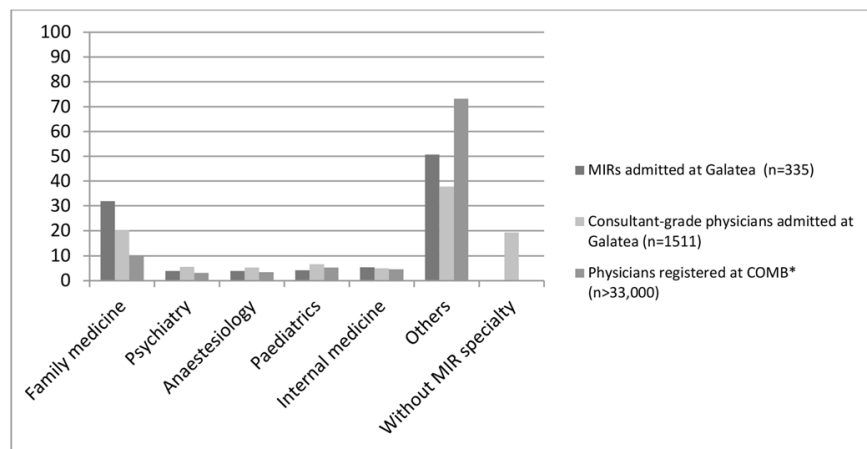

Figure 1 Main medical specialties of resident and consultant-grade physicians admitted to the Galatea Care Programme compared with those registered at the Barcelona Medical Council-Association (COMB). MIR: resident physician. 


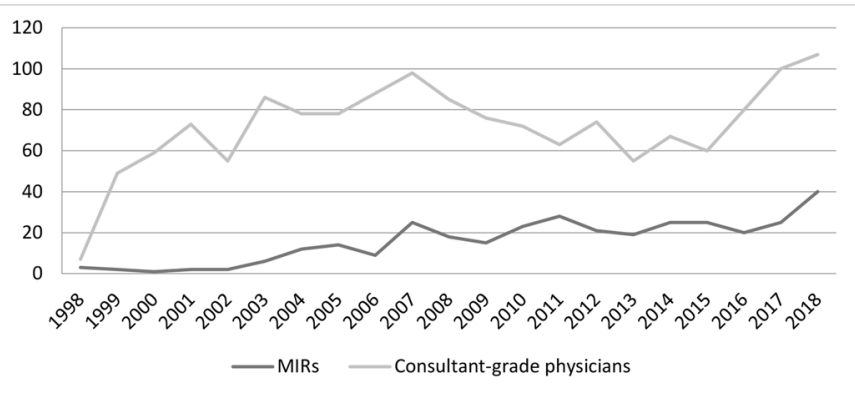

Figure 2 Evolution of resident physicians and consultantgrade physicians admissions to the Galatea Care Programme for Sick Physicians. MIR: resident physician.

were no statistically significant differences in sociodemographic, working status and clinical variables between residents and consultant-grade physicians after excluding physicians without an official specialist title.

After focusing on the residents' subsample, no significant differences between junior and senior residents were found (see table 3 ).

\section{DISCUSSION}

This study provides a valuable insight into the main trends of resident physicians' admissions to a specialised mental health programme. In fact, the percentage of residents among all admitted physicians is clearly higher than in the reference population. Data on residents admitted to the programme also reveal certain sociodemographic and clinical features of those asking for help when suffering from mental disorders. Apart from the fact that the resident physician training is a highly demanding learning period, the study findings may also indirectly show the positive effect of prevention interventions for residents and tutors developed by the Galatea Foundation over the last decade with the aim of promoting healthier coping strategies and enhancing voluntary help seeking when needed.

A clear upward trend in the number of referrals to the programme was observed during this 20 -year period. The Galatea Foundation preventive interventions for residents and their tutors started in 2009 and may have influenced the progressive increase of residents' admissions in the last decade. The fact that consultant-grade and resident physicians predominantly ask voluntarily for help(more than $90 \%$ of self-referrals in both cases) may alsosupport the hypothesis of the effectiveness of a programme of this nature (free, easily accessible and highly confidential) to overcome the physicians' reluctance to seek specialised treatment when needed. In a previous study, age at admission progressively declined since the programme started back in $1998^{39}$ and a similar trend has been reported in the UK's free access, voluntary treatment programme. ${ }^{32}$ The fact that the percentage of residents in the study was higher than in the reference population (all graduated physicians registered at the COMB) may be due to the highly demanding nature of this professional period that is known to increase the risk of developing mental disorders. ${ }^{67}$ However, it could also be related to their increased confidence in seeking help at the programme when suffering from mental distress and/or be related to wider societal changes which have made mental health issues less taboo.

Significantly, family medicine is the most common specialty among residents and it is also higher than in the reference population in both residents and consultantgrade physicians. Reasons behind this finding need to be more deeply explored in the future. However, besides specific stressors family physicians may be potentially exposed to compared with other specialists, it could be

Table 2 Results of a multivariate logistic regression analysis determining the association of sociodemographic and clinical variables according to professional condition (residents or consultant-grade physicians)

\begin{tabular}{|c|c|c|c|c|}
\hline Variables & $B^{\star}$ & Wald & $p$ value & OR $(95 \% \mathrm{Cl})$ \\
\hline Age & 0.25 & 160.8 & $<0.001$ & 1.29 (1.24 to 1.34$)$ \\
\hline Gender & 0.17 & 0.79 & 0.37 & 1.19 (0.81 to 1.73$)$ \\
\hline Married/living partner & -0.5 & 5.73 & 0.02 & 0.61 (0.4 to 0.91$)$ \\
\hline Children & 0.33 & 1.4 & 0.24 & 1.39 (0.81 to 2.41$)$ \\
\hline Regular salary & -1.79 & 23.58 & $<0.001$ & 0.17 (0.08 to 0.34$)$ \\
\hline On sick leave & 0.29 & 1.8 & 0.18 & 1.34 (0.87 to 2.06$)$ \\
\hline Mood disorders* & -0.11 & 0.04 & 0.85 & 0.9 (0.28 to 2.86$)$ \\
\hline Adjustment disorders ${ }^{*}$ & -0.27 & 0.28 & 0.6 & 0.76 (0.28 to 2.08$)$ \\
\hline Anxiety disorders* & -0.62 & 1.53 & 0.22 & $0.54(0.2$ to 1.44$)$ \\
\hline Personality disorders ${ }^{*}$ & -0.45 & 0.74 & 0.39 & 0.64 (0.23 to 1.79$)$ \\
\hline Schizophrenia and other psychotic disorders* & -0.56 & 0.66 & 0.42 & 0.57 (0.15 to 2.19$)$ \\
\hline Other disorders ${ }^{\star}$ & 0.86 & 1 & 0.32 & 2.36 (0.44 to 12.64$)$ \\
\hline
\end{tabular}

OR: Odds Ratio; Cl: Confidence Interval

`The reference condition was 'Substance Use Disorders'. 
Table 3 Comparison of junior versus senior residents admitted to the Galatea Care Programme for Sick Physicians (PAIMM)

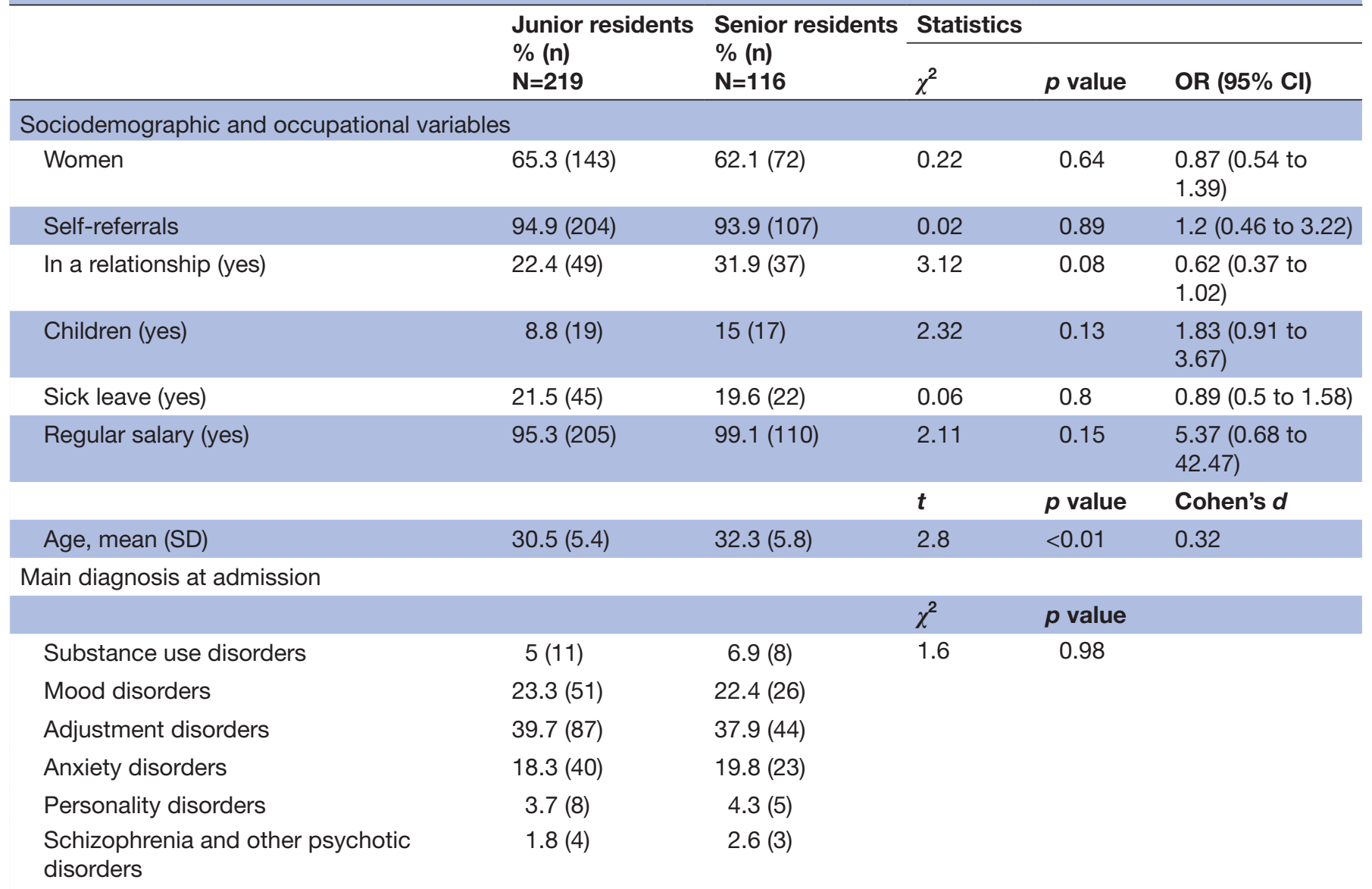

$\chi^{2}$ : Chi square test; OR: Odds Ratio; Cl: Confidence Interval

${ }^{*}$ Cohen's d was calculated for quantitative variable

hypothesised that tutors could also play a more effective role in promoting help seeking among them, as family medicine consultant-grade physicians are also more likely to be admitted to the programme. ${ }^{41}$

Gender differences were not significant between groups or when comparing senior and junior residents. However, there is a higher percentage of women admitted to the programme and this may be related to several factors. In recent years, women represent around $65 \%$ of all graduated medical students accessing the MIR system. On the other hand, some studies have pointed to a higher risk of women residents presenting mental disorders than men ${ }^{1011}$ but others fail to prove this relationship. ${ }^{612}$ However, a recent study found that women physicians were more likely to voluntarily seek help in this Physicians' Health Programme than men. ${ }^{42}$ They also came at a younger age and addictive behaviours were less prevalent than in men.

The most prevalent main diagnoses at admission were adjustment disorders, something that can be related to the multiple stressors resident physicians have to face during this transitional life stage ${ }^{67}$ although they were also the most common mental disorders among consultantgrade physicians accessing the programme. Asking for help whenfeeling unable to cope with stressful life events can be interpreted as a healthier coping strategy than avoiding help seeking in those circumstances. It may also potentially reduce the risk of developing maladaptive strategies such as self-medication and/or alcohol or drug use. ${ }^{43}$ The increasing number of younger physicians admitted to specialised treatment programmes such as the Barcelona's or the UK's ${ }^{32}$ could also be interpreted positively, as being consequences of better training and more empathetic attitudes to mental health together with a lower stigma and shame among them when admitting they suffer from a mental disorder. However, at the same time, it could be related to a lowering in the threshold of younger physician generations to tolerate distress and to cope with high job demands. On the other hand, it cannot be ignored that conditions of all physicians working at healthcare systems in Europe have worsened in recent years, ${ }^{41445}$ especially following the 2008 Great Recession budget cuts.

Mood and anxiety disorders different from adjustment disorders were also frequent among both resident and consultant-grade physicians. This finding is also in line with what has been reported in other studies. ${ }^{16} 32$ It could be hypothesised that mental distress may begin 
early during Medical School training and accompanies physicians during their professional career. ${ }^{46}{ }^{47}$ In fact, we found no differences between junior and senior residents clinical profiles, pointing to similar mental health disorders during that specific learning period.

Substance use disorder prevalence in our sample was lower than the estimated prevalence among physicians in Spain, where around $20 \%$ are expected to meet criteria for hazardous drinking and around 10\% recognize that they are self-medicate with psychoactive drugs to cope with stress. ${ }^{13}{ }^{14}$ Data on cannabis consumption among younger physicians also point to an under self-reported phenomenon. Two Galatea Foundation studies on the healthy habits of resident physicians working in Catalonia also showed higher rates of hazardous drinking and use of self-prescribed sedatives compared to those found in our study. ${ }^{13}$ The lower prevalence of addiction found in the Galatea sample may point to greater difficulties in asking for help among residents when there is substance misuse. This couldbe due to the stigma associated with suffering from a severe mental disorders (including addictions) but also to the fear of the potential negative consequences of admitting having a substance use problem.

The main methodological weaknesses of this study were: (1) its design, as it was a retrospective chart review; (2) the diagnoses were not obtained after a structured interview; and (3) the lack of data in terms of personality traits and/or other psychosocial aspects that could enrich the comprehension of the similarities and differences between groups.

As our research group has remarked in previous studies, these findings should be interpreted cautiously as the specific procedures and characteristics of our PHP need to be considered when generalising our conclusions to other countries. ${ }^{39}$

\section{CONCLUSIONS}

Residency training is known to be a highly demanding learning period both from the emotional and professional perspective. The results of this study help underscore that resident physicians progressively seem to feel more confident in seeking help when suffering from mental disorders. The nature of the Galatea's programme (free, easily accessible and highly confidential) may help to overcome the physicians' reluctance to seek specialised treatment when needed. Other reasons behind this trend could be more deeply analysed in the future with qualitative studies, and the mid-term to long-term effects of this type of programme intervention may be assessed with longitudinal studies. These findings should also be carefully considered by medical educational institutions in order to review their learning and environmental strategies. Implementing preventive programmes focusing on how to identify and cope with mental distress and fostering voluntary help seeking if there is a mental disorder should be accompanied by offering free, easy access, highly confidential and reliable mental health programmes. Addictive behaviours among residents should also be adequately assessed as they may be an under-reported phenomenon that not only may worsen these physicians' well-being but also may pose risk to their practice safety.

\section{Author affiliations}

${ }^{1}$ Integral Care Programme for Sick Health Professionals, Galatea Clinic, Barcelona, Catalonia, Spain

${ }^{2}$ Psychiatry, Mental Health and Addiction Research Group, VHIR, CIBERSAM,

Barcelona, Catalonia, Spain

${ }^{3}$ Mental Health, Benito Menni, Adult Mental Health Service, L'Hospitalet de Llobregat, Catalonia, Spain

${ }^{4}$ Department of Psychiatry, Vall d'Hebron University Hospital, Barcelona, Catalonia, Spain

${ }^{5}$ Outpatient Service, Mental Health Service of Gracia, Barcelona, Catalonia, Spain ${ }^{6}$ ACE Alzheimer Center, Fundacio ACE, Barcelona, Catalonia, Spain

Acknowledgements We want to thank Dr. Carme Bule and the COMB registration unit for their help with some data included in this study.

Contributors MDB and SV-C designed the study. SV-C, GO, MFM and GN performed the bibliographic search. SV conducted the statistical analysis. MDB, SV-C, GN and SV wrote the different versions of the manuscript. JAR-Q and EB significantly contributed to the discussion and correction of the final version. The main guarantor of this study was MDB.

Funding The authors have not declared a specific grant for this research from any funding agency in the public, commercial or not-for-profit sectors.

Competing interests None declared.

Patient and public involvement Patients and/or the public were not involved in the design, or conduct, or reporting, or dissemination plans of this research.

Patient consent for publication Not applicable.

Ethics approval Approval for chart review, data analysis and reporting was obtained from the Vall d'Hebron Hospital University Ethics Committee (PR (AG) 160/2015_v2). All physicians sign an informed consent form before being admitted to the programme. Patient anonymity is safeguarded before admission in order to protect confidentiality. Surnames are changed to conceal identity; first names are also changed according to patient preference; and real names are only disclosed with the patient's agreement or if there is an imminent risk to the patient or others.

Provenance and peer review Not commissioned; externally peer reviewed.

Data availability statement Data are available upon reasonable request. No data are available due to the high confidentiality procedures of the Galatea Care Programme.

Open access This is an open access article distributed in accordance with the Creative Commons Attribution Non Commercial (CC BY-NC 4.0) license, which permits others to distribute, remix, adapt, build upon this work non-commercially, and license their derivative works on different terms, provided the original work is properly cited, appropriate credit is given, any changes made indicated, and the use is non-commercial. See: http://creativecommons.org/licenses/by-nc/4.0/.

\section{ORCID iDs}

María Dolores Braquehais http://orcid.org/0000-0001-7314-0045

Gemma Nieva http://orcid.org/0000-0003-2630-1218

\section{REFERENCES}

1 ACGME. Accreditation Council for graduate medical education, 2019. Available: https://www.acgme.org/Residents-and-Fellows/ Welcome [Accessed 14 Nov 2019].

2 NHS. Health careers, 2015. Available: https://www.healthcareers.nhs. uk/ [Accessed 14 Nov 2019].

3 The Royal Australian College of General Practitioners (RACGP). Registrars, 2019. Available: https://www.racgp.org.au/education/ registrars [Accessed 14 Nov 2019].

4 Pardo JF. Formación especializada en España: del internado rotatorio a la troncalidad. Educ Medica 2015;16:57-67.

5 Freire J-M, Infante A, de Aguiar AC, et al. An analysis of the medical specialty training system in Spain. Hum Resour Health 2015;13:42. 
6 Koran LM, Litt IF. House staff well-being. West J Med 1988;148:97-101.

7 Lebensohn P, Dodds S, Benn R, et al. Resident wellness behaviors: relationship to stress, depression, and burnout. Fam Med 2013;45:541-9.

8 Tyssen R, Vaglum P. Mental health problems among young doctors: an updated review of prospective studies. Harv Rev Psychiatry 2002;10:154-65

9 Brooks SK, Gerada C, Chalder T. Review of literature on the mental health of doctors: are specialist services needed? J Ment Health 2011;20:146-56.

10 Nogueira-Martins LA, Jorge MR. Natureza E magnitude do estresse Na Residência Médica. Rev Assoc Med Bras 1998;44:28-34.

11 Dyrbye LN, Thomas MR, Huntington JL, et al. Personal life events and medical student burnout: a multicenter study. Acad Med 2006;81:374-84

12 Earle L, Kelly L, strategies C. Coping strategies, depression, and anxiety among Ontario family medicine residents. Can Fam Physician 2005;51:242-3.

13 Salamero M, Baranda L. Estudio longitudinal sobre La salud, estilos de vida Y condiciones de trabajo de Los miR de Cataluña. Barcelona, 2018. Available: https://www.fgalatea.org/Upload/ Documents/5/4/542.pdf

14 Salamero M, Baranda L, Mitjans A. Estudio longitudinal sobre La salud, estilos de vida Y condiciones de trabajo de Los miR. Barcelona, 2015. Available: https://www.fgalatea.org/Upload/ Documents/5/2/523.pdf

15 Blancafort X, Masachs E, Valero S. Estudio sobre La salud de Los residentes de Cataluña. Barcelona, 2009. Available: https://www. fgalatea.org/pdf/estudi_mir_cast.pdf

16 Mata DA, Ramos MA, Bansal N, et al. Prevalence of depression and depressive symptoms among resident physicians. JAMA 2015;314:2373.

17 Fagnani Neto R, Obara CS, Macedo PCM, et al. Clinical and demographic profile of users of a mental health system for medica residents and other health professionals undergoing training at the Universidade federal de São Paulo. Sao Paulo Med J 2004;122:152-7.

18 Matheson KM, Barrett T, Landine J, et al. Experiences of psychological distress and sources of stress and support during medical training: a survey of medical students. Acad Psychiatry 2016;40:63-8.

19 Vargas-Cáceres S, Mantilla MF, Ortega G, et al. Diagnóstico dual en médicos residentes: Una revisión sistemática. Adicciones 2020;32:281.

20 Spiers J, Buszewicz M, Chew-Graham C, et al. Who cares for the clinicians? the mental health crisis in the GP workforce. $\mathrm{Br} J$ Gen Pract 2016;66:344-5.

21 Garelick Al. Doctors' health: stigma and the professional discomfort in seeking help. Psychiatrist 2012;36:81-4.10.1192/pb.bp.111. 037903

22 Fox FE, Doran NJ, Rodham KJ, et al. Junior doctors' experiences of personal illness: a qualitative study. Med Educ 2011;45:1251-61.

23 Wallace JE, Lemaire JB, Ghali WA. Physician wellness: a missing quality indicator. Lancet 2009;374:1714-21.

24 de Oliveira GS, Chang R, Fitzgerald PC, et al. The prevalence of burnout and depression and their association with adherence to safety and practice standards: a survey of United States anesthesiology trainees. Anesth Analg 2013;117:182-93.

25 Shanafelt TD, Mungo M, Schmitgen J, et al. Longitudinal study evaluating the association between physician burnout and changes in professional work effort. Mayo Clin Proc 2016;91:422-31.

26 Fahrenkopf AM, Sectish TC, Barger LK, et al. Rates of medication errors among depressed and burnt out residents: prospective cohort study. BMJ 2008;336:488-91.

27 Shanafelt T, Goh J, Sinsky C. The business case for investing in physician well-being. JAMA Intern Med 2017;177:1826-32.
28 Shanafelt TD, Balch CM, Bechamps G, et al. Burnout and medical errors among American surgeons. Ann Surg 2010;251:995-1000.

29 Kitson A, Marshall A, Bassett K, et al. What are the core elements of patient-centred care? A narrative review and synthesis of the literature from health policy, medicine and nursing. $J$ Adv Nurs 2013;69:4-15.

30 Cameron D, Katch E, Anderson P, et al. Healthy doctors, healthy communities. J Ambul Care Manage 2004;27:328-38.

31 Lobelo F, de Quevedo IG. The evidence in support of physicians and health care providers as physical activity role models. Am J Lifestyle Med 2016;10:36-52

32 Gerada C. THE WOUNDED HEALER : Report on the first 10 years of Practitioner Health Service. London: NHS, 2018.

33 Accreditation Council for Graduate Medical Education. 2015 ACGME Symposium on physician well-being, 2015. Available: https://www. acgme.org/What-We-Do/Initiatives/Physician-Well-Being/2015ACGME-Symposium-on-Physician-Well-Being [Accessed 15 Nov 2019].

34 Ey S, Moffit M, Kinzie JM, et al. Feasibility of a comprehensive wellness and suicide prevention program: a decade of caring for physicians in training and practice. J Grad Med Educ 2016;8:747-53.

35 Martinez S, Tal I, Norcross W, et al. Alcohol use in an academic medical school environment: a UC San Diego healer education assessment and referral (hear) report. Ann Clin Psychiatry 2016;28:85-94.

36 Tricoastal Consortium for the Canadian Medical Foundation. A descriptive framework for physician health services in Canada, 2016. Available: http://medicalfoundation.ca/wp-content/uploads/2016/09/ 7.b-TCC-Descriptive-Framework-Survey-Companion-FINAL-May24-2016.pdf

37 The Royal Australasian College of Physicians (RACP). RACP support program, 2019. Available: https://www.racp.edu.au/fellows/ physician-health-and-wellbeing/i-need-support/racp-supportprogram [Accessed 15 Nov 2019].

38 Mitjans A, Vilardell M. Fostering healthy practice among physicians. BMJ Opin, 2019. Available: https://blogs.bmj.com/bmj/2019/09/ 25/fostering-healthy-practice-among-physicians/ [Accessed 2 Feb 2021].

39 Braquehais MD, Valero S, Matalí JL, et al. Promoting voluntary help-seeking among doctors with mental disorders. Int J Occup Med Environ Health 2014;27:435-43.

40 American Psychiatric Association. Diagnostic and Statistical Manual of Mental Disorders. In: Text revision (DSM-IV-TR. 4th edn. Washington DC: American Psychiatric Association, 2000.

41 Braquehais MD, Nieva G, González-Irizar O, et al. Family physicians with mental disorders admitted to a physicians' health programme: what can be learned? Fam Pract 2020;37:655-60.

42 Braquehais MD, Arrizabalaga P, Lusilla P, et al. Gender differences in demographic and clinical features of physicians admitted to a program for medical professionals with mental disorders. Front Psychiatry 2016;7:3-7.

43 Boisaubin EV, Levine RE. Identifying and assisting the impaired physician. Am J Med Sci 2001;322:31-6.

44 Karanikolos M, Mladovsky P, Cylus J, et al. Financial crisis, austerity, and health in Europe. Lancet 2013;381:1323-31.

45 Lionis $\mathrm{C}$, Petelos $\mathrm{E}$. The impact of the financial crisis on the quality of care in primary care: an issue that requires prompt attention. Qual Prim Care 2013;21:269-73.

46 Quek TT-C, Tam WW-S, Tran BX, et al. The global prevalence of anxiety among medical students: a meta-analysis. Int J Environ Res Public Health 2019;16:2735.

47 Puthran R, Zhang MWB, Tam WW, et al. Prevalence of depression amongst medical students: a meta-analysis. Med Educ 2016;50:456-68. 